\title{
SUBGLACIAL WATER PRESSURES AND THE SHAPE OF SUBGLACIAL CONDUITS
}

\author{
By ROger LeB. HOOKE, \\ (Department of Geology and Geophysics, University of Minnesota, Minneapolis, Minnesota 55455, \\ U.S.A.) \\ TRON LAUMANN, \\ (Norwegian Water Resources and Energy Administration, P.O. Box 5091, N-0301 Oslo 3, Norway) \\ and JACK KOHLER
}

(Department of Geology and Geophysics, University of Minnesota, Minneapolis, Minnesota 55455,

U.S.A.)

\begin{abstract}
Measured subglacial water pressures are frequently higher than theoretical values calculated by assuming that subglacial conduits are straight and either circular or semi-circular in shape. While this may be attributed to errors in the estimates of conduit roughness or ice viscosity, we suggest here an alternative explanation: namely, that the conduits are actually broad and low rather than semi-circular. Good agreement between measured and calculated pressures can be obtained by assuming that the cross-sectional shape of conduits resembles the space between the arc of a circle and its chord. The angle subtended by the arc, $\theta$, is treated as an adjustable parameter. In four cases studied, $\theta$ ranged from $2^{\circ}$ to $36^{\circ}$.
\end{abstract}

\section{INTRODUCTION}

It is commonly assumed that, in the steady state, the rate of melting on the wall of an englacial or subglacial conduit due to viscous dissipation balances closure of the conduit by flow of the ice (Röthlisberger, 1972; Shreve, 1972). Using this assumption, Röthlisberger (1972, equation (20)) derived an expression relating the pressure gradient in subglacial conduits to conduit characteristics and the steady water discharge. By integrating this equation up-glacier from the terminus, using the water pressure at the terminus as a boundary condition, he calculated water pressures as a function of distance from the terminus. His calculations of the water pressure beneath Gornergletscher, however, did not agree well with a water pressure that was measured about $1.2 \mathrm{~km}$ up-glacier from the terminus. To achieve agreement, Röthlisberger had to assume not only that the conduit was unusually rough, but also that the ice-viscosity parameter, $B$, was only $1.0 \mathrm{bar} \mathrm{a}^{1 / 3}$, which is significantly less than the value of $\sim 1.6 \mathrm{bar} \mathrm{a}^{1 / 3}$ that is widely accepted for temperate ice (e.g. Hooke, 1981; Paterson, 1981, p. 39; Lliboutry and Duval, 1985, p. 215). As strain-rates are inversely proportional to the cube of the viscosity, Röthlisberger was, in effect, assuming that the basal ice was a factor of 4 softer than normal.

Lliboutry (1983, p. 222) suggested that conduits close faster in zones of high pressure on the stoss sides of irregularities in the bed, and that failure to take this into account might explain the low value of $B$ that Röthlisberger needed. Hooke $(1984$, p. 185) suggested, alternatively, that Röthlisberger might have misinterpreted the water-pressure data, which, in fact, showed quite low pressures in late summer. Hooke's calculations suggested that conduits on the down-glacier sloping bed beneath the outermost $2.2 \mathrm{~km}$ of Gornergletscher should be at atmospheric pressure.
Iken and Bindschadler (1986) also compared waterpressure data that they obtained from bore holes on Findelengletscher with pressures calculated using Röthlisberger's model. They, too, found that agreement was best when they used a value of $B$ that was substantially lower than accepted values, and suggested a number of possible causes of such enhanced plasticity. Among these were the presence of impurities or unfrozen water, the non-isotropic stress state, and the possibility of transient creep. In addition, they suggested that the flow path was probably quite sinuous, a characteristic not taken into consideration in Röthlisberger's model.

While many of these suggestions have merit and may contribute to the high water pressures observed, we pursue here an alternative mentioned briefly by Lliboutry (1983, p. 222) and by Iken and Bindschadler $(1986$, p. 114) but not developed by them: namely, that the channel shape assumed in the Röthlisberger model is incorrect. Specifically, we investigate the possibility that the channels are broad and low, a shape of ten observed at the termini of valley glaciers. Such a shape might well develop through melting low on the conduit walls during periods of low flow, and through drag on the bed which inhibits closure of the conduit near the bed. Walder (personal communication, May 1989) has also found that broad low conduits are likely to form when the bed over which the water is flowing consists of non-cohesive material that can be transported by the water. First, however, we present water-pressure data for two additional glaciers. Later we show that these data, too, cannot be explained by the Röthlisberger model as it stands.

WATER-PRESSURE MEASUREMENTS ON AUSTDALSBREEN AND STORGLACIÄREN

In connection with hydro-electric development, water-pressure measurements have been made on Austdalsbreen, an outlet glacier from Jostedalsbreen, Norway. Eight holes were drilled to the base of the glacier, two a few meters apart in each of four locations (Fig. 1). Water pressures in the holes tended to increase gradually during the winter, and in some cases more rapidly in the early spring (Fig. 2). In late May or early June, pressures dropped abruptly and began to oscillate diurnally. In order to compare the measurements with calculated pressures, we have estimated the mean late-winter/early-spring water levels at each of the four locations in Figure 2 (see starred lines), and plotted these at the appropriate locations on Figure 1. Where pressures in Figure 2 exceeded the water- 


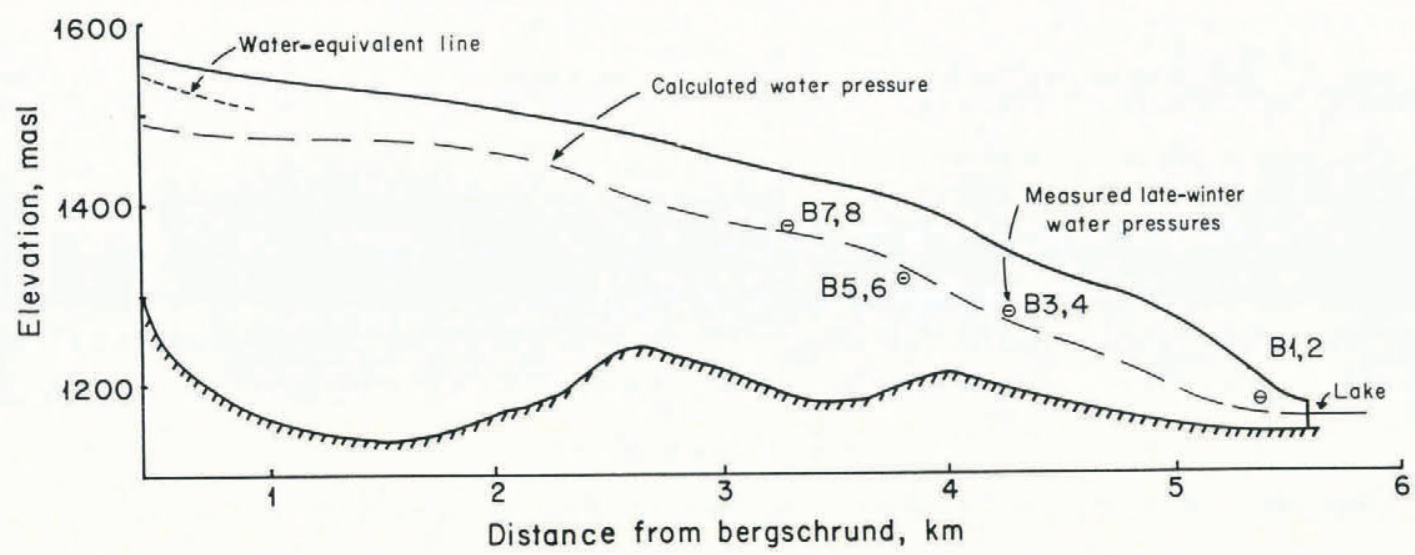

Fig. 1. Longitudinal section of Austdalsbreen showing locations of bore holes, mean late-winter water levels in the holes, and an hydraulic grade line calculated with $k=10 \mathrm{~m}^{1 / 3} \mathrm{~s}^{-1}, B=1.6 \mathrm{bar} a^{1 / 3}$, and $\Omega=13$.
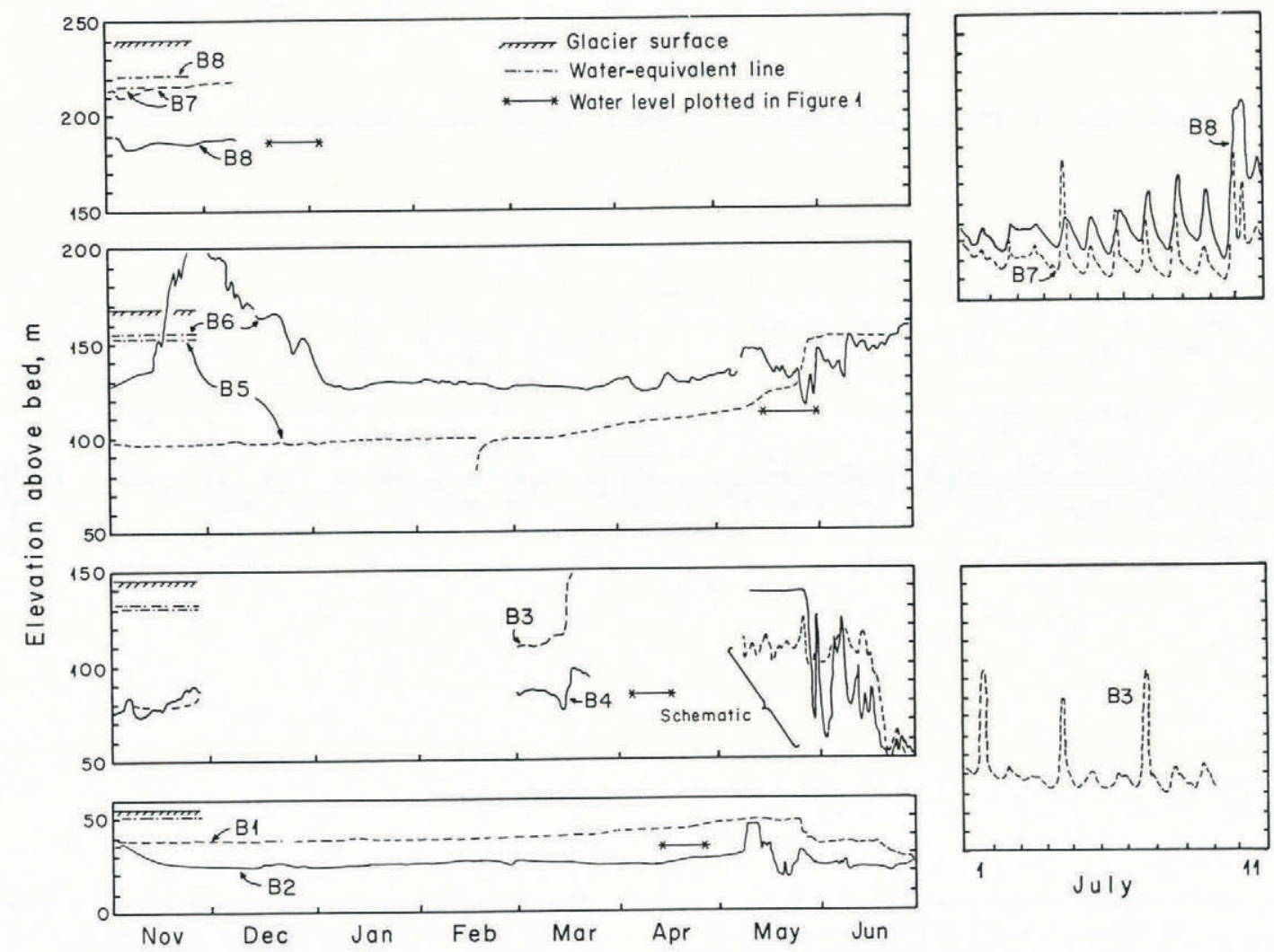

Fig. 2. Water-pressure measurements on Austdalsbreen. Locations of holes are shown in Figure 1. Gaps in record are due to periodic failure of recording system.

equivalent line, it was assumed that a local pressure, not representative of average conditions at the base of the glacier, was being measured. These parts of the record were ignored in selecting the water levels to plot in Figure 1.

On Storglaciären, a valley glacier in northern Sweden, water-pressure measurements have been made in many bore holes for varying lengths of time over the past 7 years (Hooke and others, 1989). A general characteristic of these measurements is that, above the riegel that lies near the middle of the ablation area (Fig. 3), water levels are almost invariably high and remarkably constant. In contrast, below the riegel, diurnal oscillations are common during the summer. However, some winter data suggest that pressures here begin to rise in the late autumn and early winter, and are relatively constant in late spring (Hooke and others, 1989, fig. 3a).

\section{MODIFICATION OF RÖTHISBERGER'S MODEL}

Calculations of subglacial water pressure as a function of distance from the termini of Austdalsbreen and
Storglaciären were made with the use of the equation:

$$
G^{11 / 8}-0.316 G^{3 / 8} \mathrm{~d} P / \mathrm{d} x=\Omega D k^{-3 / 4}(n B)^{-n} Q^{-0.25} \cos ^{-11 / 8} \beta \Delta P^{n}
$$

where $\mathrm{d} P / \mathrm{d} x$ is the pressure gradient along the course of the conduit; $G=\left(\mathrm{d} P / \mathrm{d} x+\rho_{\mathrm{w}} g \tan \beta\right)$, where $\rho_{\mathrm{w}}$ is the density of water, and $g$ is the acceleration due to gravity; $D$ is a constant involving, among other quantities, the densities of ice and water, the latent heat of fusion, and $g$; $k$ is the reciprocal of the Manning roughness of the conduit; $n$, taken to be 3 here (Hooke, 1981), and $B$ are the constants in Glen's flow law for ice, $\dot{\varepsilon}=(\tau / B)^{n}$; $Q$ is the water discharge; $B$ is the slope of the bed, taken as positive when the bed slopes downward in the direction of flow; $\Delta P$ is the difference between the pressure in the ice adjacent to the conduit and that in the water in the conduit; and $\Omega$ is a conduit-shape factor which is explained below. This equation is identical to Röthlisberger's (1972) equation (20) except for the term $\Omega$.

If we approximate the shapes of conduits by the space 


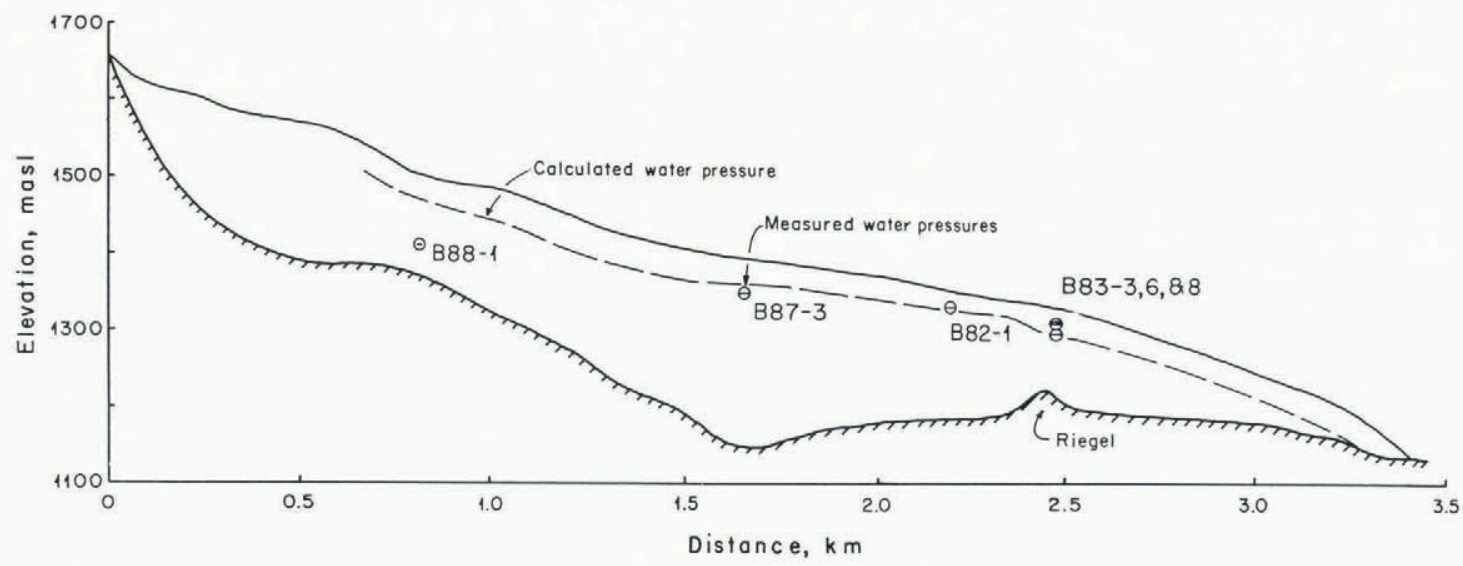

Fig. 3. Longitudinal section of Storglaciären showing locations of bore holes, mean water levels in the holes, and an hydraulic grade line calculated with $k=10 \mathrm{~m}^{1 / 3} \mathrm{~s}^{-1}, B=1.6 \mathrm{bar} \mathrm{a}^{1 / 3}$, and $\Omega=150$. Hole $B 88-1$ was $\approx 200 \mathrm{~m}$ from the line of the profile, at a point where the glacier was $\approx 30 \mathrm{~m}$ thicker than shown. Furthermore, the water-level measurement was made on 30 June 1988, 10-15d after the lower part of the glacier had accelerated into its summer regime. For all these reasons, the measurement may not be representative of winter conditions.

between the chord of a circle and the arc subtended by that chord (Fig. 4), the cross-sectional area of the conduit, $A$, is $r^{2}(\theta-\sin \theta) / 2$, and the wetted perimeter, $p$, is $r(\theta+$ $2 \sin \theta / 2$ ). Röthlisberger's development can be modified to reflect this conduit shape if an expression can be obtained for the closure of such conduits.

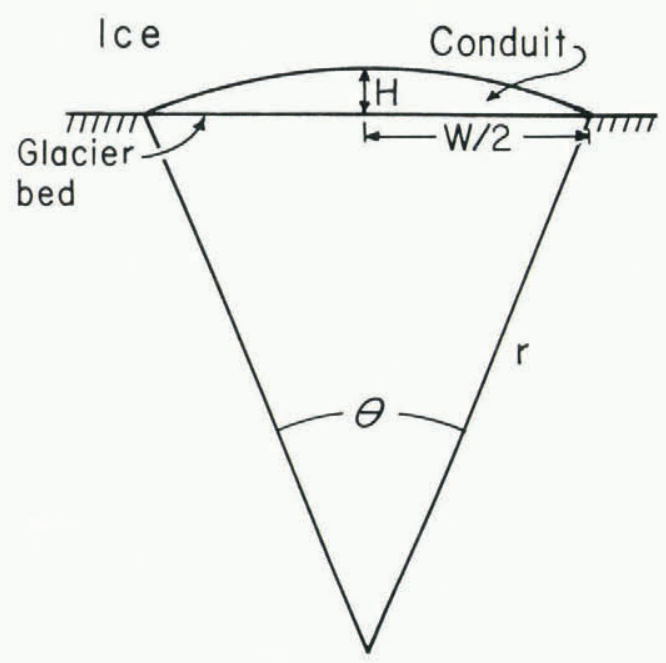

Fig. 4. Sketch showing conduit geometry assumed.

We suspected that the closure rate might lie between limiting values obtained by replacing the conduit radius in Nye's (1953) theory first with the conduit height, $H$ (Fig. 4), and then by its half-width, $W / 2$. We thus used the mean of these two lengths in place of the radius in the relation for conduit closure in Röthlisberger's (1972, equation (6)) theory. This leads to Equation (1) with

$$
\Omega=\frac{\theta(1-\cos \theta / 2+\sin \theta / 2)(\theta+2 \sin \theta / 2)^{\frac{1}{2}}}{2^{5 / 2} \pi^{1 / 4}[(\theta-\sin \theta) / 2]^{5 / 4}} .
$$

To test our approximation for the closure rate, we modelled numerically the closure of conduits such as that in Figure 4, using a finite-element program (Hanson, 1990). As will be discussed further below, the discrepancy between the closure rate obtained by using $(H+W / 2) / 2$ to approximate the conduit radius in Nye's theory and the rate obtained from the numerical calculation averaged $22 \%$, and was $53 \%$ in the worst of the four cases studied. Thus, for the purposes at hand, this approximation seems adequate.

It is convenient to express $\Omega$ in terms of the fraction, $\delta$, by which the accepted value of $B$ must be multiplied to obtain agreement between calculated and observed water pressures, thus:

$$
\Omega=\delta^{-3} \text {. }
$$

$\delta$ is plotted as a function of $\theta$ in Figure 5 .

By choosing $\theta<\pi$, an observed pressure gradient or

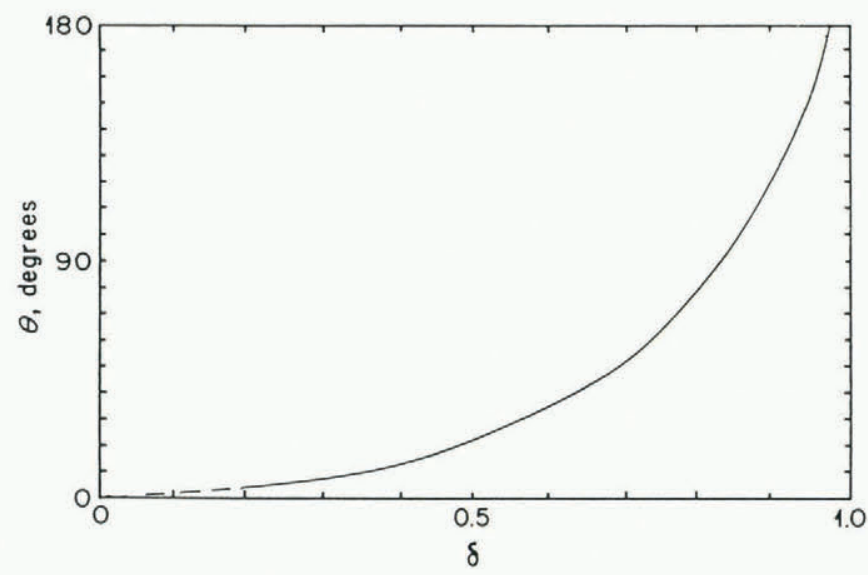

Fig. 5. Relationship between $\theta$ and the factor, $\delta$, by which $B$ must be reduced to obtain the same hydraulic grade line.

hydraulic grade line can be modelled without reducing $B$ below the accepted value of $1.6 \mathrm{bar} \mathrm{a}^{1 / 3}$. For example, Röthlisberger used a value of $B$ of $1.0 \mathrm{bar} \mathrm{a}^{1 / 3}(\delta=0.61)$. This would be equivalent to a value of $\theta$ of about $36^{\circ}$ (Fig. 5; Table I). Similarly, the value of $B$ that gives the best fit between Iken and Bindschadler's (1986) observed (figs 4 and 5) and calculated (fig. 14) water pressures was about 0.3 bar a $^{1 / 3} \quad(\delta=0.18)$, which would correspond to $\theta$ $\approx 2^{\circ}$.

It should be noted that, contrary to the above hypothesis, a semi-circular or parabolic subglacial conduit has been observed beneath Gornergletscher a short distance down-stream from the Gornersee (Röthlisberger, 1972, fig. 11). Lliboutry (personal communication, December 1989) suggests that this may be because this particular conduit carries much larger discharges than those considered elsewhere in this paper. Alternatively, this conduit may have developed under non-steady-state flow conditions associated with the draining of the Gornersee. When melting greatly exceeds closure, conduits will be full and the effects of drag on the bed during closure of the conduit will be negligible. As noted, both of these effects will favor semi-circular rather than broad, low conduit cross-sections. 
TABLE I. CHANNEL CHARACTERISTICS

\begin{tabular}{lccccrrrr} 
Glacier & $Q$ & $B$ & $\delta$ & $\Omega$ & $\theta$ & $W$ & $H$ & Error $^{*}$ \\
& $\mathrm{~m}^{3} \mathrm{~s}^{-1}$ & \multicolumn{1}{c}{ bar a $^{1 / 3}$} & & & & & & $\%$ \\
Austdalsbreen & 0.05 & 0.7 & 0.42 & 13 & 14 & 3.0 & 0.09 & 7 \\
Findelengletscher & 1.0 & 0.3 & 0.18 & 150 & 2 & 28.0 & 0.12 & 53 \\
Gornergletscher & 10.0 & 1.0 & 0.61 & 4.4 & 36 & 10.6 & 0.85 & 19 \\
Storglaciären & 0.01 & 0.3 & 0.18 & 150 & 2 & 5.6 & 0.03 & 12
\end{tabular}

*The error is the discrepancy between closure rates calculated using $(H+W / 2) / 2$ to approximate the conduit radius in Nye's (1953) theory and those calculated numerically. The latter were higher in all cases.

\section{COMPARISON WITH MEASUREMENTS ON AUSTDALS- BREEN AND STORGLACIÄREN}

Hydraulic grade lines were calculated for Austdalsbreen and Storglaciären using Equation (1). Following Röthlisberger, the conduit roughness was taken to be $10 \mathrm{~m}^{1 / 3} \mathrm{~s}^{-1}$ in both cases. The calculation for Austdalsbreen assumed a late-winter discharge of $0.05 \mathrm{~m}^{3} \mathrm{~s}^{-1}$, while that for Storglaciären used $0.01 \mathrm{~m}^{3} \mathrm{~s}^{-1}$. Both figures are estimates. Austdalsbreen terminates in a lake, so it has not been feasible to measure the winter discharge. In the case of Storglaciären, late-winter discharges have been observed, but not measured. The values of $\theta$ required to obtain the agreement shown in Figures 1 and 3 were about $14^{\circ}$ and $2^{2}$, respectively $(\Omega \approx 13$ and 140$)$.

\section{CHANNEL GEOMETRIES}

The actual geometries of the channels corresponding to the values of $\theta$ thus obtained can be calculated by first determining $r$ (Fig. 4) from:

$$
r=Q^{3 / 8} k^{-3 / 8} \frac{(\theta+2 \sin \theta / 2)^{1 / 4}}{[(\theta-\sin \theta) / 2]^{5 / 8}}\left(\rho_{\mathrm{w}} g\right)^{3 / 16} G^{-3 / 16} .
$$

The resulting values of $H$ and $W$ are shown in Table I. The calculations suggest channels, particularly for Findelengletscher and Storglaciären, that are wider and shallower than may be reasonable. However, two $\sim 0.5 \mathrm{~m}$ wide, 10 to $>30 \mathrm{~mm}$ deep channels (in addition to a $0.3 \mathrm{~m}$ diameter semi-circular conduit) were observed at the bed of the Norwegian glacier, Bondhusbreen, beneath $\sim 160 \mathrm{~m}$ of ice (Hooke and others, 1985, p. 392). Furthermore, the numerical modelling suggests that using $(H+W / 2) / 2$ to approximate the conduit radius in the closure-rate calculations underestimates the actual rate. Correcting for this error would increase the values of $H$ and decrease those of $W$ shown in Table I. Finally, we stress that neither the calculations nor the field data are sufficiently accurate to justify conclusions other than that the channels may well be several times wider than they are high.

\section{DISCUSSION}

The mean value of $\theta$ from these four examples is $\sim 14^{\circ}$ $(\Omega \sim 13)$, so we will use this as a typical value for purposes of further discussion. Such a value would correspond to a reduction in $B$ to $\sim 0.7 \mathrm{bar} \mathrm{a}^{1 / 3}$, or to $\sim 40 \%$ of its normal value. This would result in a $\sim 16 x$ enhancement of the strain-rate.

Such enhancement could occur if the water content of the ice were in excess of $7 \%$ (Duval, 1977), but this is unreasonably high. It is, for example, almost triple the highest measured by Vallon and others (1976, p. 24) in a $187 \mathrm{~m}$ core from Vallee Blanche on Mont Blanc. Softening of the ice could also be due to the presence of other impurities, but available data on the effects of different species of impurity do not appear to be extensive; a suggestion of the impurity content required to produce such a softening can be obtained from Jones and Glen's (1969, p. 17) experiments at $-20 \mathrm{~K}$ on ice doped with $\mathrm{HF}$, a particularly potent impurity, though not common in glacier ice. An HF concentration of $67 \mathrm{ppm}$ resulted in only a five-fold increase in strain-rate, and indications were that the effect would probably decrease as the temperature rose towards the melting point. Concentrations of more common impurities are probably typically $<\sim 10 \mathrm{ppm}$ in temperate glaciers (Harrison, 1972, p. 26). Thus, it is unlikely that impurities alone could account for the softness of the ice.

Iken and Bindschadler (1986, p. 114) suggested that the softness of the ice might be attributed, in part, to transient creep in the changing stress field present in ice flowing over an irregular bed. This is open to question. The ice near the bed of a glacier will have recrystallized and developed a $c$-axis fabric with a preferred orientation. It will thus be deforming in tertiary creep. When such ice moves into a location with a different stress field, it will already have a high dislocation density and the resulting transient-creep phase lasts only about a half hour (personal communication from L. Lliboutry, December 1989). Furthermore, owing to the fabric, it is equally or perhaps more likely that the ice will be stiffer rather than softer in the new stress field. Thus, it seems unlikely that we can appeal to transient creep to explain the apparent softness of the ice around tunnels.

Lliboutry (1983, p. 222) suggested that the apparent softness of ice around subglacial conduits might be due to enhanced closure rates on the stoss sides of irregularities on the bed. If $\Delta P$ were doubled on the stoss sides of bumps and vanished on the lee sides where ice could become separated from the bed, the enhancement could be as much as a factor of 4. This is sufficient to account for the observed water pressures beneath Gornergletscher (Lliboutry, 1983 , p. 222), but substantially more separation would be required to account for the observed water pressures on the other three glaciers. Such extensive separation is unrealistic.

Iken and Bindschadler (1986, p. 114-15) suggested that part of the discrepancy between observed and calculated subglacial water pressures can be attributed to the sinuosity of the subglacial flow paths. As $\mathrm{d} P / \mathrm{d} x$ is calculated along the flow path, the more sinuous the flow path, the higher the pressure at a point a given straight line distance from the margin. To test this possibility, the computer program used to calculate the energy grade lines in Figures 1 and 3 was modified to allow the user to specify the sinuosity. With $B=1.6 \mathrm{bar} \mathrm{a}^{1 / 3}$, sinuosities of 6 and 30 were required to obtain reasonable agreement with measurements on Austdalsbreen and Storglaciären, respectively. These seem quite improbable.

\section{CONCLUDING STATEMENT}

Clearly, all of the above processes could be working in concert to produce the high conduit-closure rates suggested by the measured water pressures. However, rather than the ice being unusually soft, our suggestion that the conduits are broad and low, is at least as reasonable as any others that have been suggested. Furthermore, it appears that in most instances it is the only one that could, alone, account for the observed pressures. The major weakness in the development is one that pervades the theoretical literature on water pressures in subglacial channels: the need to rely on Nye's (1953) theory, in some form, to calculate the closure rates of the channels despite the fact that virtually 
all of the important assumptions that Nye made in his theoretical development are violated in the natural situation.

\section{ACKNOWLEDGEMENTS}

Many of the ideas in this paper were developed while the senior author was enjoying the hospitality of the Norwegian Water Resources and Energy Administration. The authors would like to acknowledge the role that stimulating conversations with $\mathrm{B}$. Wold and other members of the Glaciology Office played in the paper. Financial support for the field work on Storglaciären was provided by the Swedish Natural Science Research Council and the U.S. National Science Foundation (DPP-8414190, DPP-8619086, and INT-8712749). Important items of permanent equipment were purchased with funds generously provided by the Wallenberg Foundation of Sweden. The critical comments of L. Lliboutry and J. Walder resulted in significant improvements in the paper.

\section{REFERENCES}

Duval, P. 1977. The role of the water content on the creep rate of polycrystalline ice. International Association of Hydrological Sciences Publication 118 (Symposium at Grenoble 1975 - Isotopes and Impurities in Snow and Ice), 29-33.

Hanson, B.H. 1990. Thermal response of a small ice cap to climatic forcing. J. Glaciol., 36(122), 53-60.

Harrison, W.D. 1972. Temperature of a temperate glacier. $J$. Glaciol., 11(61), 15-29.

Hooke, R.LeB. 1981. Flow law for polycrystalline ice in glaciers: comparison of theoretical predictions, laboratory data, and field measurements. Rev. Geophys. Space Phys., 19(4), 664-672.
Hooke, R.LeB. 1984. On the role of mechanical energy in maintaining subglacial water conduits at atmospheric pressure. J. Glaciol., 30(105), 180-187.

Hooke, R.LeB., B. Wold, and J.O. Hagen. 1985. Subglacial hydrology and sediment transport at Bondhusbreen, southwest Norway. Geol. Soc. Am. Bull., 96(3), 388-397.

Hooke, R.LeB., P. Calla, P. Holmlund, M. Nilsson, and A. Stroeven. 1989. A 3-year record of seasonal variations in surface velocity, Storglaciären, Sweden. J. Glaciol., 35(120), 235-247.

Iken, A. and R.A. Bindschadler. 1986. Combined measurements of subglacial water pressure and surface velocity of Findelengletscher. Switzerland: conclusions about drainage system and sliding mechanism. J. Glaciol., 32(110), 101-119.

Jones, S.J. and J.W. Glen. 1969. The effect of dissolved impurities on the mechanical properties of ice crystals. Philos. Mag., 19(157), 13-24.

Lliboutry, L. 1983. Modifications to the theory of intraglacial waterways for the case of subglacial ones. $J$. Glaciol., 29(102), 216-226.

Lliboutry, L. and P. Duval. 1985. Various isotropic and anisotropic ices found in glaciers and polar ice caps and their corresponding rheologies. Ann. Géophys., 3(2), 207-224.

Nye, J.F. 1953. The flow law of ice from measurements in glacier tunnels, laboratory experiments and the Jungfraufirn borehole experiment. Proc. R. Soc. London, Ser. A, 219(1139), 477-489.

Paterson, W.S.B. 1981. The physics of glaciers. Second edition. Oxford, etc., Pergamon Press.

Röthlisberger, H. 1972. Water pressure in intra- and subglacial channels. J. Glaciol., 11(62), 177-203.

Shreve, R.L. 1972. Movement of water in glaciers. $J$. Glaciol., 11(62), 205-214.

Vallon, M., J.-R. Petit, and B. Fabre. 1976. Study of an ice core to the bedrock in the accumulation zone of an alpine glacier. J. Glaciol., 17(75), 13-28. 